\title{
Estudio de costos de mantenimiento en helicópteros militares mediante la aplicación del costeo abc
}

\author{
Mario Javier Giraldo`, Diana Paola Tapiero Paredes, Mónica García Castillo \\ Institución Universitaria Politécnico Grancolombiano, Bogotá, Colombia
}

FECHA DE ENTREGA: 19 DE MARZO DE 2013

FECHA DE EVALUACión: 11 DE NOVIEMBRE 2013

FECHA DE APROBACIÓN: 6 DE MAYO DE 2014

\begin{abstract}
Resumen Bajo información de la Fuerza Aérea Colombiana e investigaciones del mantenimiento en helicópteros, se evidencian mecanismos de control y clasificación de actividades. Esto se desarrolla al incorporar una metodología que permite evaluar, medir y simplificar la manera de manejar los costos de las operaciones realizadas en el mantenimiento de aeronaves. Se enfoca en helicópteros MIL MI 17, para tener claridad sobre los procesos y las actividades llevadas a cabo.
\end{abstract}

\begin{abstract}
According to information provided by the Colombian Air Force and to investigations on helicopter maintenance, it is possible to highlight control and activity classification mechanisms. This is developed when incorporating a methodology that enables evaluating, measuring, and simplifying the way people manage the costs of the operations carried out when providing aircraft maintenance. In order to understand the processes and the activities developed, it is important to clarify that this paper focuses on helicopters MIL MI 17.
\end{abstract}

Palabras Clave: helicóptero, mantenimiento, costeo ABC, militar, fallas.

Keywords: helicopter, maintenance, ABC costing, military, flaw.

* magirald@poligran.edu.co 


\section{Introducción}

Los helicópteros tienen en la actualidad dos aplicaciones. Una civil y otra militar. Dentro de la militar, es de gran importancia el contar con un mantenimiento eficaz y continuo. Al mismo tiempo se debe llevar un costeo de lo invertido en este aspecto. El desarrollo muestra el trabajo que han realizado las fuerzas armadas colombianas, mediante entrevistas e información pública. Por esta misma razón, no se pueden mostrar algunos procesos internos del proceso de implementación y resultados cuantificados.

\section{Descripción del helicóptero}

Aeronave sustentada y propulsada por uno o más rotores horizontales, cada uno formado por dos o más aspas. Los helicópteros están clasificados como aeronaves de alas giratorias para diferenciarlos de las aeronaves de ala fija. Éstos crean sustentación con las aspas que rotan alrededor de un eje vertical. [3]

Los helicópteros están compuestos principalmente por rotor principal, palas, rotor de cola, transmisión, ejes, engranajes, estructura general y servos. El mantenimiento de un helicóptero es más complejo que otras aeronaves debido a su autonomía de vuelo.

Una de las ventajas del helicóptero viene dada por el rotor. éste proporciona sustentación sin que la aeronave se esté desplazando. Lo que permite realizar despegues y aterrizajes verticales sin necesidad de pista. Existen dos tipos de helicópteros: civil y militar. Este último tiene armamento, mayor autonomía y tamaño, un distinto tipo de plataforma y mayor costo.

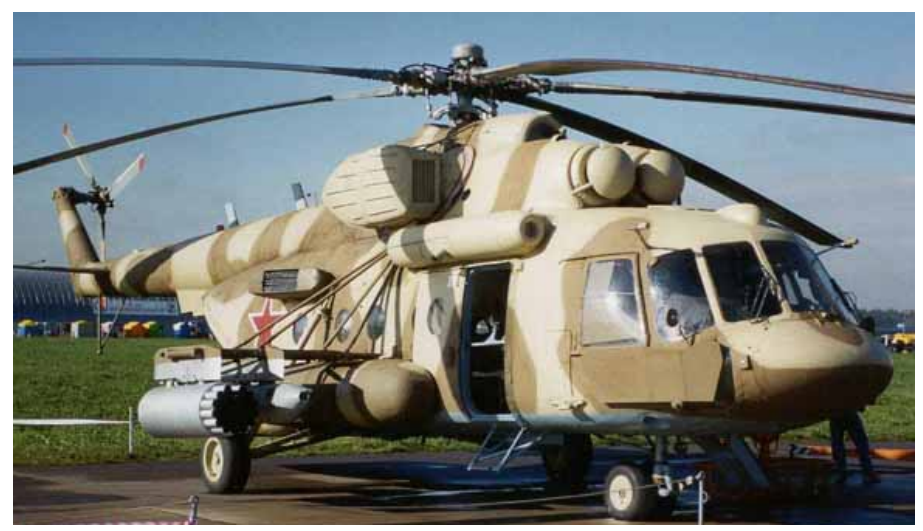

Figura 1. 


\subsection{Inicios de los helicópteros en Colombia}

El helicóptero llega a Colombia, en 1953 con la entrada en servicio del equipo Hiller OH-23B Raven. El helicóptero apoya las fuerzas militares mediante la incorporación de equipos. En 1988 se compraron 10 Sikorsky UH-60A Black Hawk y en 1990, 20 UH-1H. [2]

Algunos de estos tienen equipos con sensores de anomalías magnéticas. Entre otros elementos que ayudan al combate. Los Helicópteros Militares se clasifican por tamaño: Livianos, Medianos y Pesados. El tipo específico es usado dependiendo las características de la misión en cuanto a la capacidad necesaria y tiempo de vuelo.

\section{Partes de los helicópteros}

Las principales partes de los helicópteros son:

\subsection{Rotor principal}

Conjunto de piezas que por sus exigencias en vuelo requiere de un mantenimiento casi constante. Todos los tornillos deben estar bien ajustados y pegados en los casos que sean necesarios.

\subsection{Palas}

Están relacionadas con el rotor principal, y la tensión de las mismas en los porta-palas. Su objetivo es evitar vibración, mediante un ajuste especial. Si están flojas, pueden golpear en la aceleración. Si están apretadas no pueden acomodarse en vuelo. Para que un juego de palas esté equilibrado debe tener el mismo peso y centro de gravedad.

\subsection{Rotor de cola}

El rotor de cola es más simple que el principal, por lo que el mantenimiento es mucho más simple, pero de igual importancia.

\subsection{Transmisión}

La transmisión va desde el motor hasta los dos rotores. Los helicópteros tienen las siguientes partes: embrague, ejes, engranajes, correas o tubos, rodamientos, acoples, piñones, entre otras piezas secundarias.

\section{5. $\quad$ Ejes}

Los tipos de ejes son: principal, cola, spinddle y flybar. No requieren mantenimiento, pero no se pueden doblar. 


\subsection{Engranajes}

Los tipos de engranajes son: principal, corona cola y piñones de cola. Estos requieren de una inspección periódica, para evitar el gasto o saltos.

\subsection{Estructura general}

Compuesta por el chasis. Existen varios tipos y se les realiza una revisión periódica en cuanto a las piezas y tornillos que lo componen.

\subsection{Servos}

Los servos comprenden: paso, alerón y elevador, cola y acelerador. Requieren estar en óptimas condiciones siempre, por lo que se les realiza revisiones periódicas. Las partes generales del helicóptero llevan a su clasificación.

\section{Clasificación de los helicópteros militares}

En la industria militar esta depende del tamaño.

\subsection{Liviano}

Los helicópteros livianos fueron desarrollados por el China Helicopter Design Institute y Change Aircraft Indsutry Group (CAIG). Se diferencian por poseer un radar en su proa.

Desarrollan tres tipos de misiones en el campo militar: enlace, exploración y apoyo táctico. Tiene capacidad máxima de transporte para cuatro soldados totalmente equipados. Las referencias en Colombia son las siguientes: [6]

- BELL 206 III

- A555

- B0 105

- $\mathrm{H} 500$

Para mayor capacidad de soldados se encuentran los helicópteros medianos.

\subsection{Mediano}

Además de poder llevar más soldados totalmente equipados, pueden llevarlos a mayor velocidad y distancia. Su capacidad máxima es de 19 soldados equipados para el combate en un radio de $460 \mathrm{~km}$.

Desarrollan dos tipos de misiones: rebusca y rescate de tripulantes derribados en un radio de $520 \mathrm{~km}$. El alcance máximo de este tipo de helicópteros en una misión de trasladó es de $1.050 \mathrm{~km}$. [6]

- HUEY II

- BELL 212 


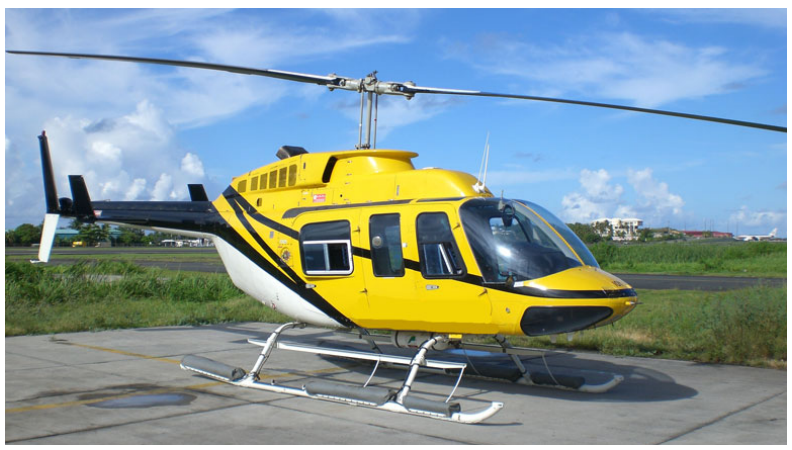

Figura 2.

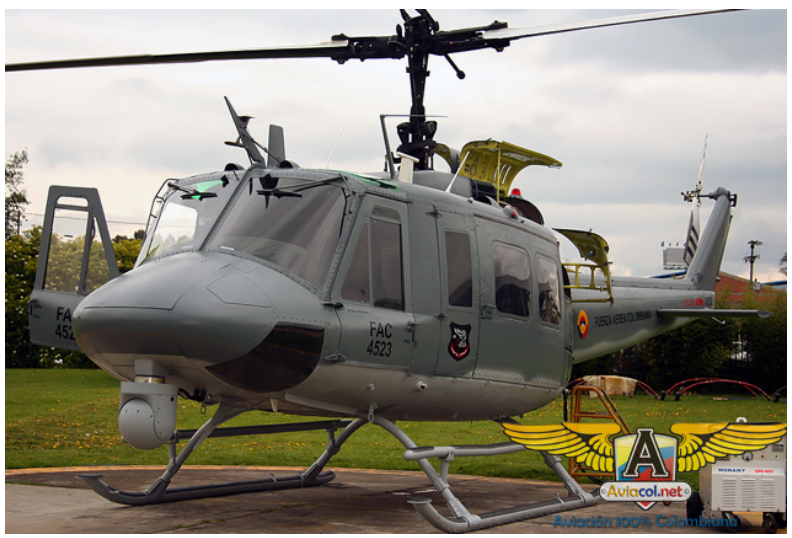

Figura 3.

\subsection{Pesado}

Este tipo de helicóptero es capaz de transportar 24 soldados totalmente equipados. Tiene cohetes y misiles guiados antitanque. Algunas de las misiones que desarrollan son: ambulancia aérea, reconocimiento, observación, búsqueda y salvamento, mando aéreo para tanques y misión de comunicaciones. Las referencias en Colombia son las siguientes: [6]

- HUEY II

- MIL MI 17 IV

- MIL MI $17 \mathrm{~V}$

- MIL MI 17 MD

Cada tipo de helicóptero tiene unas políticas especiales de mantenimiento. Pero el enfoque del documento es en los helicópteros de tipo pesado, referencia MIL MI 17. 


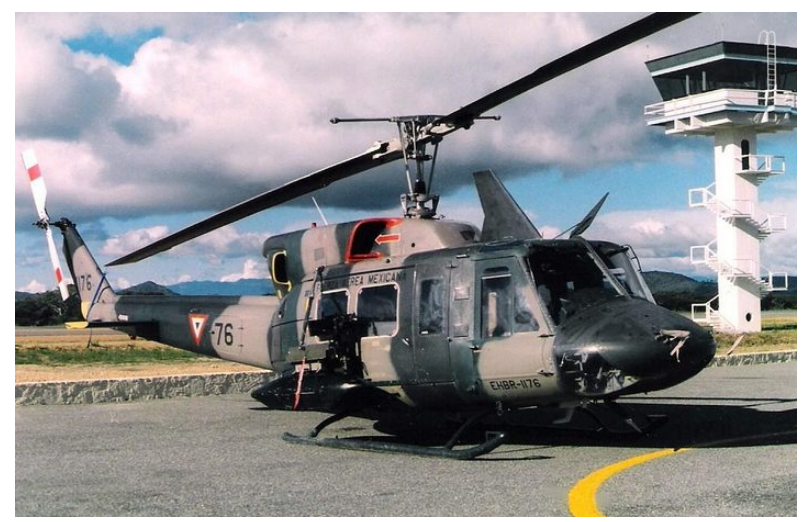

Figura 4.

\section{Políticas de mantenimiento helicóptero: MIL MI 17}

Los Helicópteros MI-17 son aeronaves multipropósito. Estos son diseñados y fabricados en Rusia. Usados para todo tipo de misiones de vuelo. Permiten el desarrollo de las misiones, aun en condiciones de riesgo Nuclear, Biológico y Químico (NBQ). Se emplean en lo militar, civil y humanitario. Los Helicópteros MI-17 proporcionan la capacidad de extender y soportar operaciones de artillería. Usa armamento pesado terrestre, naval y aéreo.

\subsection{Niveles de mantenimiento}

Los Helicópteros militares en Colombia tienen cuatro niveles de mantenimiento. Los primeros tres se realizan en el territorio nacional y el último se hace el país de origen del helicóptero. En cada uno de estos niveles se desarrollan diversas actividades, tal como se enuncian a continuación: [6]

\section{Primer nivel: inspección general}

- Verificación de averías externas.

- Palas y hélices.

- Aplicación de aditamentos.

\section{Segundo nivel: conexión de partes}

- Verificación de potencia del motor.

Tercer nivel: armar - desarmar

- Reemplazar piezas dañadas. 


\section{Cuarto nivel: fallas en estructura}

- Rotor de cola.

- Fragmentación del helicóptero en dos o más partes con posibles pérdidas de vidas humanas.

\subsection{Secuencias de inspección}

La secuencia de inspecciones que se hacen al helicóptero son Pre-Vuelo y PostVuelo. (ver figura 5): [1]
A. Acercamiento al helicóptero.
B. Parte delantera.
C. Lado derecho del helicóptero.
D. Batalón de cola lado derecho.
E. Pylón y conjunto de rotor de cola.
F. Batalón de cola lado izquierdo.
G. Lado izquierdo del helicóptero.
H. Parte inferior del helicóptero.
I. Cabina de Carga/Pasajeros.
J. Parte superior lado derecho.
K. Parte superior lado izquierdo.

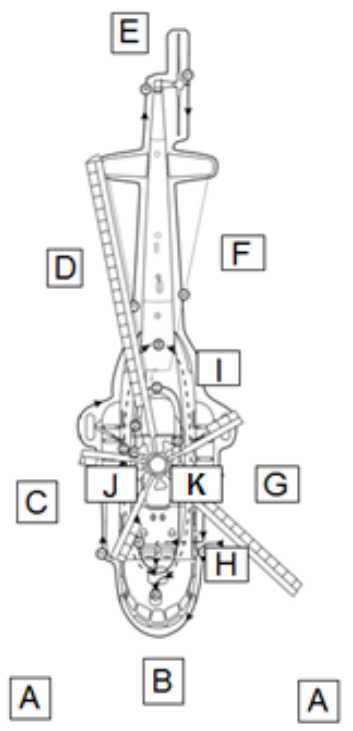

Figura 5. 


\section{Costos de mantenimiento helicóptero MIL MI 17}

Los costos del mantenimiento del helicóptero MIL MI 17 están descritos en la figura 6. [6]

\begin{tabular}{|c|c|c|c|c|}
\hline TIPO & HELICÓPTERO & PROCEDENCIA & \begin{tabular}{|l|} 
MANT. \\
MENSUAL
\end{tabular} & \begin{tabular}{|l|}
1 HORA \\
DE VUELO \\
\end{tabular} \\
\hline \multirow{3}{*}{ PESADOS } & MIL MI 17 - IV & RUSO & \multirow{3}{*}{$\$ 11.400 .000$} & \multirow{3}{*}{$\$ 4.500 .000$} \\
\hline & MIL MI 17 - V & RUSO & & \\
\hline & MIL MI 17 - MD & RUSO & & \\
\hline
\end{tabular}

Figura 6.

Estos helicópteros utilizan combustible JP 8 (Jet Propulsion 8), que es derivado del queroseno. La política de mantenimiento es la siguiente:

- Cada 2000 horas de vuelo, se efectúa una inspección hasta el Nivel de Mantenimiento 2.

- Cada 4000 horas de vuelo, Se efectúa una inspección hasta el Nivel de Mantenimiento 3.

Para el análisis de los costos de mantenimiento de los Helicópteros militares se realiza un análisis a partir de la metodología ABC. Con la metodología de Costos Basados en Actividades, (Activity Based Costing) se busca analizar los niveles de mantenimiento, según la clasificación de los mismos para el Helicóptero Mil Mi 17.

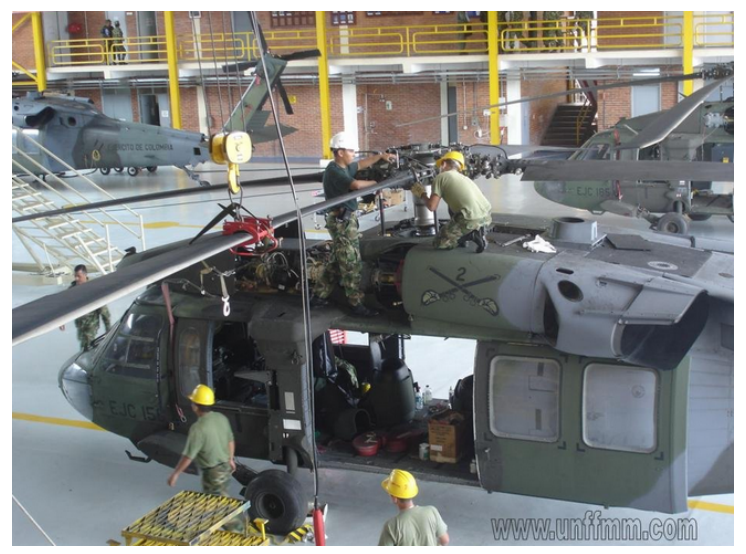

Figura 7. 


\section{Costos $\mathrm{ABC}[4]$}

El Método de Costos Basado en Actividades (ABC) mide el costo y desempeño de las actividades, basado en el uso de recursos. Este costeo plantea la diferenciación de un modelo contable y lo pone en un modelo gerencial en donde los recursos son consumidos por las actividades. Muestra la necesidad de examinar los procesos dentro de cada área de la empresa, junto con la clasificación de tareas y trabajos para determinar los costos. Se deben eliminar todas aquellas tareas que entorpezcan o no ayuden al desempeño eficaz de los factores productivos.

\subsection{Pasos para implementación de costos ABC}

Para realizar el costeo por actividades se deben seguir los siguientes pasos:

- Determinar el recurso.

- Identificar actividades.

- Identificar los elementos de costos de las actividades.

- Determinar los generadores de costos.

- Asignar los costos de las actividades.

- Asignar los costos directos a los productos.

Las actividades son clasificadas y ordenadas según su influencia en el producto. Pueden ser por producto, por lote, por línea de producto o por empresa. Hay que tener en cuenta la frecuencia de trabajo que use la actividad.

\subsection{Procedimiento para la clasificación de actividades en el Costeo ABC}

Para la clasificación de actividades se debe tener en cuenta:

Análisis de procesos o actividades: este proceso realiza un análisis del diseño de las actividades y así comprende las actividades que cada caso implica.

Identificación de los elementos del costo de cada proceso: se clasifican las tareas entre primarias o de apoyo y se identifican los inductores de costo para cada tarea.

Determinación del costo de los procesos operativos: se realiza el cálculo de los costos de las actividades primarias y de apoyo y finalmente se obtiene el total del costo de los procesos operativos.

La ventaja del desarrollo de Costos $\mathrm{ABC}$, frente a otros métodos, para este tipo de industria es dada porque tiene en la cuenta los recursos, operaciones y productos, que incluye preparación y ejecución, siendo un sistema muy completo. [8] 


\section{Ventajas Costos ABC}

- Identifica clientes, productos, proveedores, servicios u otros objetivos de costos no rentables.

- Permite calcular de forma precisa los costos, fundamentalmente determinados costos indirectos de producción, comercialización y administración.

- El modelo es aplicable a todo tipo de empresas de producción o de servicios, facilitando el proceso contable para la industria militar.

- Aporta información sobre las actividades que realiza la empresa, permitiendo conocer cuáles agregan valor y cuáles no, dando la posibilidad de poder reducir o eliminar estás que no agregan valor.

- Permite relacionar los costos con sus causas,

- Identifica a los clientes, productos y canales menos provechosos.

- Determina los contribuidores y detractores verdaderos del desempeño financiero.

Estas ventajas apoyan el manejo contable y un mejor control sobre los procesos de mantenimiento en las fuerzas armadas.

Basados en esta metodología, se realiza el análisis y clasificación de actividades para la estimación del mantenimiento de Helicópteros MIL MI 17.

\section{Aplicación del costeo ABC en los helicópteros militares}

Dado que el método de costo basado por actividades (Costos ABC) mide el costo y desempeño de las actividades basado en el uso de los recursos, se establecen los siguientes recursos principales para evaluar las actividades en el mantenimiento de los helicópteros militares:

- Mano de Obra

- Partes Componentes

- Repuestos

- Tiempos de mantenimiento

- Capacidad Técnica

\subsection{Clasificación de actividades}

Las actividades establecidas para efectuar la evaluación y clasificación de costos son las siguientes:

Inspección de pre-vuelo: acercarse al helicóptero y revisar adecuadamente que el Sistema Integrado de Armamento y sub-sistemas se encuentren debidamente asegurados.

Formularios de mantenimiento: revisar y actualizar los formularios. 
Revisión ventiladores: verificar que la entrada de aire de los motores, el ventilador, el cono de escape de los motores, al APU y los tubos pitot estén destapados y libres de objetos extraños.

Revisión compartimiento: verificar que las tapas de las baterías, las tapas de los toma corriente y de la toma estática se encuentren cerradas y aseguradas.

Revisar condición: verificar el estado en que se encuentran: el blindaje, luces de navegación, espejos, indicador formación hielo, parabrisas y ventanas, tubos pitot, sistema corta cables, antenas ILS y DME, tren de nariz, estado del amortiguador, reflexión de las llantas, luz de aterrizaje y taxeo, luz anticolisión, luz de búsqueda Infrarroja, compartimiento de nariz, palas rotor principal, toma de aire de ventilación de cabina, ventana salida de emergencia, ventanas cabina de carga, la aplicación de esta metodología promueve el trabajo multidimensional bajo el principio de Pareto. [7]

Combustible: verificar que el tanque derecho de combustible se encuentre sin fugas y drenado, tapa interna y externa aseguradas, bandas de sujeción y pernos con frenado.

Cabina de carga: verificar estado de: paneles sistema eléctrico, techo cabina, asientos pasajeros, cinturones de seguridad, extintores contra incendios, compuerta y mecanismo de sujeción del sistema de carga externa, compuerta de carga y salidas de emergencia, rampa cabina de carga y salidas de emergencia, bomba hidráulica rampa y manija, luz compartimiento de carga, compartimiento de radios.

Motor: verificar que se encuentre en buen estado: sistema de rotor principal, uniones toma de aire arrancador neumático motor N.1, motor N.1, piso motor, acelerador, manetas de combustible, nivel de aceite.

\section{Desarrollo de políticas militares para el cumplimiento de las etapas, bajo indicadores de gestión en los niveles de mantenibilidad}

Partiendo de la clasificación de actividades, se generan unos niveles de mantenibilidad. Se evalúan diversos factores según lo exhaustivo de la revisión correspondiente en cada helicóptero. Cada uno de estos niveles tiene de unos requisitos académicos y tecnológicos de estricto cumplimiento sobre los cuales se destacan:

- El centro de capacitación debe contar con el aval de la Brigada de Aviación del Ejército de Colombia en los programas académicos y de vuelo. 
- Total confidencialidad de la información y reproducción de los manuales usados en instrucciones.

- Certificación de Calidad ISO 9001 en los centros de entrenamiento para el mantenimiento de helicópteros militares.

- Mínimo siete (7) años de experiencia de los centros de capacitación.

- Entre otros.

Por confidencialidad no se puede profundizar en los indicadores de gestión y en las mejoras que se dieron bajo la implementación de costos $\mathrm{ABC}$ en el mantenimiento, pero se presentan los niveles con sus controles a continuación:

\subsection{Nivel 1}

El Nivel 1 evalúa superficialmente el estado del helicóptero. Se verifica la condición de los dispositivos, chequeo de los niveles de aceite, el aseguramiento de los equipos para cada misión, entre otros. Cuentan con listas de chequeo que deben ser diligenciadas por Tripulantes No Pilotos (TNP), antes y después de cada vuelo. Basándose en la figura 5 (Secuencia de Inspección), se efectúa la verificación de estado.

Gestión de la mantenibilidad: los TNP, se encargan de hacer la verificación exhaustiva de los helicópteros bajo los Manuales de Inspección establecidos por el Ejército Nacional de Colombia

Indicadores de gestión: los indicadores de gestión manejados en este nivel se encuentran basados en las planillas y listas de chequeo con las que cuenta cada tipo de helicóptero. En este caso se tienen listas de chequeo específicas para el Helicóptero MIL MI 17. Al finalizar cada periodo se evalúan los mayores índices de cambio en los helicópteros, basados en los parámetros y limitaciones del nivel correspondiente.

\subsection{Nivel 2}

Para este nivel, se establecen y controlan las potencias de cada una de las partes principales. Según los estándares internacionales y la ficha técnica del fabricante del Helicóptero MIL MI 17, existen unos criterios sobre los cuales la medición es la adecuada para ejecutar maniobras, tal como lo apreciamos en la figura 8.

Gestión de la mantenibilidad: sobre los resultados obtenidos en la gestión la mantenibilidad, se explica el trabajo realizado apoyándose en una gráfica de factores relevantes de cada uno, para un mejor entendimiento.

Pruebas de aceleración parcial: relación entre la temperatura máxima admisible de los gases y la temperatura del aire exterior durante la comprobación de la aceleración parcial. 


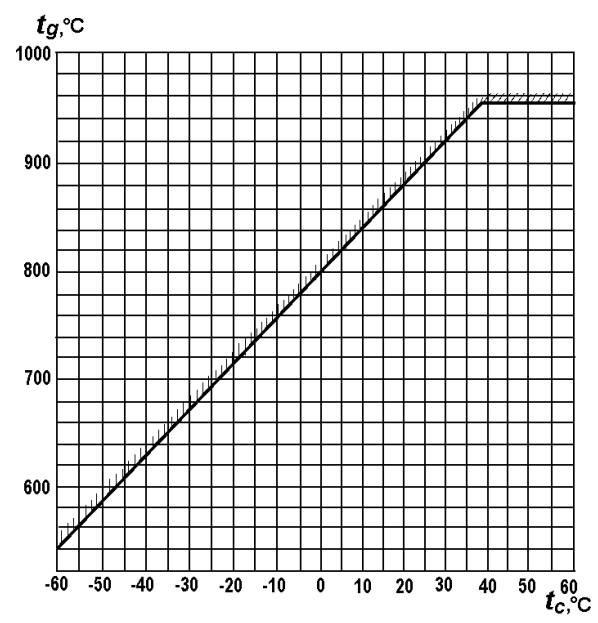

Figura 8.

Regímenes de funcionamiento de motores: función entre el número de revoluciones del turbocompresor y la temperatura del aire exterior a la entrada en el motor. Ver figura 9.

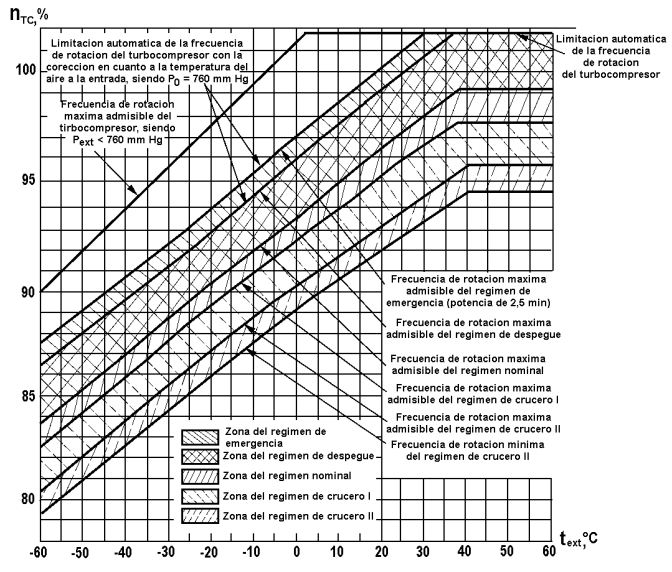

Figura 9. 
Efecto viento dentro del efecto tierra: esta gráfica determina el incremento de la masa máxima en función de la velocidad y la dirección del viento durante el despegue y el aterrizaje. Ver figura 10.

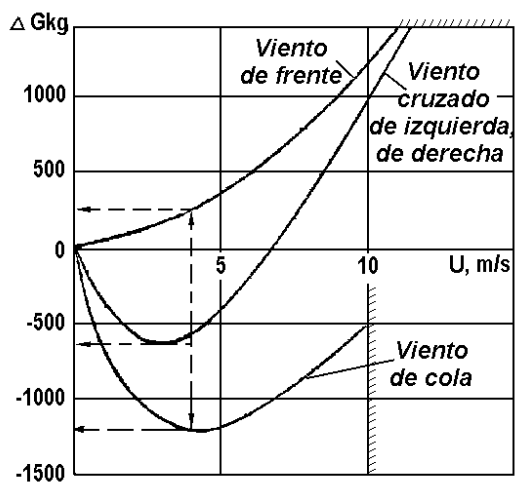

Figura 10.

Falla en un motor en vuelo de ascenso: determina la masa máxima admisible de despegue del helicóptero que corresponde a los requisitos de la categoría A (FAR-29) fallando un motor. Ver figura 11.

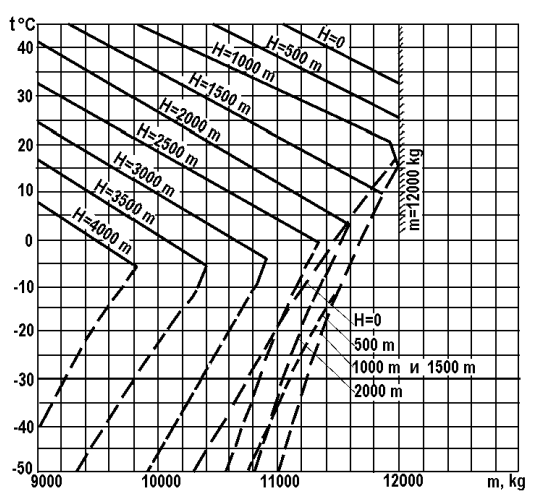

Figura 11. 
Falla en un motor de vuelo recto y nivelado: masa máxima del helicóptero en vuelo horizontal con un motor operativo, Va-ind $=120 \mathrm{~km} / \mathrm{h}(\mathrm{SAH}$ desconectado). Ver figura 12.

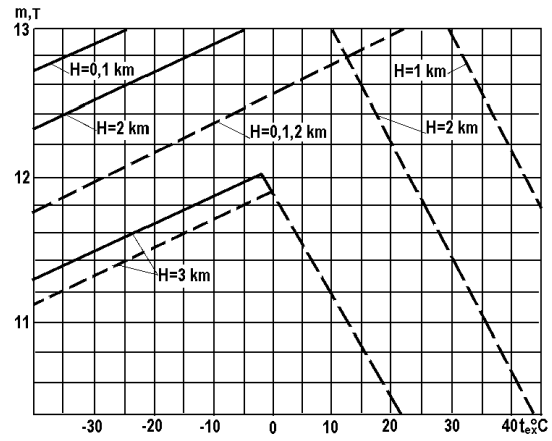

Figura 12.

Altura vs. velocidad: limitaciones de la masa de vuelo, al efectuar los vuelos estacionarios, vuelos a baja altitud y a ras de la tierra. Ver figura 13.

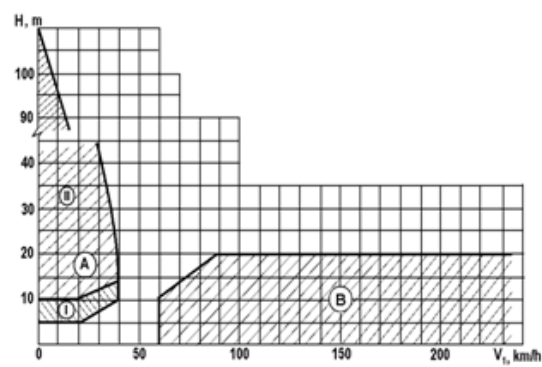

Figura 13.

Consumo de combustible: análisis de Combustible Mínimo por hora de vuelo. Ver figura 14.

Indicadores de gestión. Los indicadores de gestión para este nivel están dados por los resultados arrojados por cada una de a pruebas realizadas en laboratorio. (Laboratorios Ubicados en Tolemaida y Melgar, Colombia) 


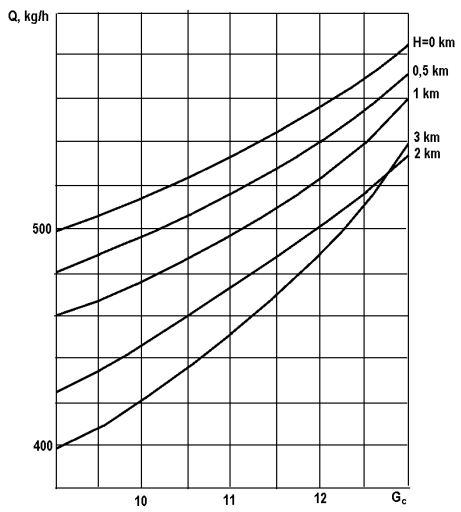

Figura 14.

\subsection{Nivel 3}

En este nivel, se contempla el desarme y reposición de piezas dañadas. Depende al mismo tiempo del tipo de helicóptero que se tenga para reparar. El límite de reconstrucción dentro de este nivel se encuentra en la estructura del helicóptero. Independiente del nivel que estos requieran existen unos costos fijos asociados a su mantenimiento. Los cuales se regulan con base en el presupuesto anual establecido y las misiones extra curriculares que se pueda presentar.

Helicópteros livianos. Este tipo de helicópteros se destaca por que se prestan a casi cualquier tipo de misión, con las inherentes limitaciones derivadas de su pequeño tamaño. Los costos asociados al mantenimiento de este tipo de helicópteros esta dado en la figura 15.

\begin{tabular}{|l|l|l|l|lr|}
\hline & HELICÓPTERO & PROCEDENCIA & MANT MENSUAL & 1 HORA DE VUELO \\
\hline \multirow{3}{*}{ LIVIANOS } & BELL 206 III & AMERICANO & $\$ 6,500,000-\$ 8,400,000$ & $\$ 2.200 .000,00$ \\
\cline { 2 - 7 } & AS 555 & FRANCES & $\$ 6,500,000-\$ 8,400,000$ & $\$ 2.200 .000,00$ \\
\cline { 2 - 7 } & BO 105 & ALEMAN & $\$$ & $1.800 .000,00$ & $\$ 50.000,00$ \\
\hline
\end{tabular}

Figura 15.

Helicópteros medianos. Este tipo de helicópteros se caracteriza por su gran capacidad en combate debido a su autonomía. Los costos asociados a este tipo de helicópteros esta dado por la figura 16, teniendo en cuenta que para estos se manejan horas de simulación. Específicamente para el helicóptero HUEY II (240 horas). 


\begin{tabular}{|l|l|l|l|l|}
\hline & HELICÓPTERO & PROCEDENCIA & MANT MENSUAL & 1 HORA DE VUELO \\
\hline \multirow{2}{*}{ MEDIANOS } & HUEY II & AMERICANO & \multirow{2}{*}{$\$ 9.900 .000,00$} & $\$ 3.400 .000,00$ \\
\cline { 2 - 3 } & BELL 212 & FRANCES & & \\
\hline
\end{tabular}

Figura 16.

Helicópteros pesados. Su principal labor radica en el transporte de soldados equipados, así como misiones de largas horas de vuelo y distancias. El helicóptero MIL MI 17 se encuentra en esta clasificación. Para el caso del helicóptero MIL MI 17- MD, (uno de los helicópteros más grandes, con los que cuenta la Fuerza Aérea Colombiana), la capacidad de transporte es de 28-35 soldados armados, con tanques de gasolina adicionales externos y con posibilidad de tener hasta 8 horas de vuelo. Ver figura 17.

\begin{tabular}{|l|l|l|l|l|}
\hline & HELICÓPTERO & PROCEDENCIA & MANT MENSUAL & 1 HORA DE VUELO \\
\hline \multirow{4}{*}{ PESADOS } & UHS60L-BLACK HAWK & RUSO & & \\
\cline { 2 - 3 } & MIL MI 17 - IV & RUSO & \multirow{4}{*}{$\$ 11.400 .000,00$} & $\$ \quad 4.500 .000,00$ \\
\cline { 2 - 3 } & MIL MI 17-V & RUSO & & \\
\cline { 2 - 3 } & MIL MI 17- MD & RUSO & & \\
\hline
\end{tabular}

Figura 17.

Gestión de la mantenibilidad. Debido a las variaciones que tiene este nivel de mantenimiento, los controles son difíciles. Pese al control que se lleva a cabo en niveles anteriores, el control sobre cada clasificación se vuelve más exhaustivo y más completo. Sin embargo, los formatos indexados previamente, convierten al siguiente nivel en un canal más acertado para la verificación de la información, evitando errores.

Indicadores de gestión. Los Indicadores de gestión en este nivel, se basan en los costos fijos de mantenimiento y las variaciones de los mismos, según las misiones a las cuales hayan tenido que ser sometidos los helicópteros. Dependiendo de las rutas o misiones, se manejan diversas horas que influyen directamente sobre los resultados obtenidos para cada una de las clasificaciones de los helicópteros asociados.

\subsection{Nivel 4}

Este nivel se presenta cuando la estructura del helicóptero se ve afectada de manera sustancial. Implica ruptura de la estructura general de la nave o del rotor de la cola. En este caso, el mantenimiento no se realiza en los laboratorios de CAMAN, (Comando Aéreo de Mantenimiento), si no en la casa matriz del helicóptero afectado. 
Gestión de la mantenibilidad. Esta gestión de mantenibilidad va ligada a las misiones a las cuales está expuesta la nave. Estas misiones, en la mayoría de las ocasiones están destinadas a los helicópteros pesados, debido a la característica de los mismos y su capacidad en tiempos de vuelo.

Indicadores de gestión. Los buenos resultados en estos indicadores, evitan pérdidas humanas. De este modo, los controles en mantenimiento y en misiones son de mayor importancia.

\section{Extensión hacia los helicópteros civiles}

El mantenimiento en los helicópteros de uso civil, es menos complejo ya que en este no se hacen inspecciones en armamentos y no se hace verificación de antiexplosivos tan detallada, ya que es menos frecuente este tipo de acontecimientos en estas aeronaves.

Básicamente el mantenimiento de estas aeronaves es el mismo, la variación es en el tipo de equipo de comunicación que cada uno de estos lleva (el de un helicóptero militar es más complejo), mientras que sus partes componentes son las mismas. Por lo tanto el chequeo de la aeronave en cuanto a mantenimiento como tal de piezas en general es semejante.

\section{Conclusiones}

- A partir de la entrevista hechas sobre el proceso para la clasificación y el control de las operaciones, llevadas a cabo en el mantenimiento preventivo y correctivo de los Helicópteros en Colombia, se puede inferir el mejoramiento de las actividades realizadas en cada una de las etapas para la reducción de costos.

- Los documentos investigados muestran que el manejo de costos $\mathrm{ABC}$ dentro de la industria militar, ayuda a generar un orden contable, dando transparencia para control interno.

- Del mismo modo la claridad en los procesos bajo los cuales la TNP, la ejecución de las labores de mantenimiento demuestra el alcance de los procesos, evitando fallas parciales o hasta mortales.

- La clasificación de niveles y actividades ante la implementación de una metodología $\mathrm{ABC}$, permite tanto a la organización como al ejecutor de las actividades tener mejores resultados, mayores controles y un mejor desempeño de las mismas.

- La claridad en los procesos genera un mejor nivel de ejecución, optimizando los tiempos y la calidad de la actividad realizada.

- Basados en estas clasificaciones, los indicadores de gestión implementados muestran de forma verídica, los resultados obtenidos mediante la estandarización de los procesos, permitiendo así que la información arrojada por el modelo sea lo más real y tangible. 


\section{Referencias}

1. Colombia, FF. MM.: Manual De Entrenamiento De Tripulación. Bogotá. (2007)

2. Fuerzas Militares, Historia. (s.f.). [en línea] Recuperado el 16 de Mayo de 2010 de http://www . fuerzasmilitares .org/aviacion/historia.html. (2010)

3. FULLPLANE. (s.f.).: Fullplane. [en línea] Recuperado el 17 de Mayo de 2010, de http://www.fullplane.com.ar/eetn4/introduccion-basica.htm. (2010)

4. Hicks, D.: El sistema de Costos basado en las Actividades (ABC): guía para su implantación en pequeñas y medianas empresas. Mexico D.F: Alfaomega. (1998).

5. Mantenimiento de Helicópteros, Galeón. (s.f.). [en línea] Recuperado el 16 de Mayo de 2010, de http://heliobsesion.galeon.com/manten_de_helis.htm. (2010)

6. Teniente, F. C.: Mantenimiento de Helicópteros. (P. Tapiero., Entrevistador) (2010).

7. Ferhan, C., Cengiz, K., Bersam, B.: A Multiattribute ABC Classification Model Using Fuzzy AHP. Istanbul Technical University. (2011).

8. Yang, X., Zhang, Q.: The Research of Military Logistics Cost Accounting. International Conference on Information Management, Innovation Management and Industrial Engineering. China. (2012). 